\title{
A Conservative Esthetic Rehabilitation of Complicated Tooth Fracture: Two Case Reports
}

\author{
Manoj Mahadeo Ramugade, Neelam Dilip Chandwani, Kishor Dattatray Sapkale, Sachin Shashikant Metkari
}

\begin{abstract}
Maxillary incisors are the most commonly involved teeth in traumatic injuries. As their esthetic and functional value is unequivocal, their treatment becomes major concern for both, the patient as well as the dentist. Various treatment modalities have been practiced for fractured anterior teeth, including composites, laminates, esthetic crown or the reattachment of fractured fragment. Among which fragment reattachment is considered to be the most conservative, natural and an esthetic approach. Reattachment of fragment could be the viable treatment option only when the tooth fragment is intact and having its good clinical approximation with the remaining tooth structure. In addition, the overall success of this treatment modality depends upon the fragment's extend of dehydration (time lapsed), patient cooperation and also the skill of the operator for such case selection. This article discusses the management of complicated crown fractures of anterior teeth which were managed successfully in a conservative manner.
\end{abstract}

Keywords: Fragment reattachment, Incisors, Complicated tooth fracture.

How to cite this article: Ramugade MM, Chandwani ND, Sapkale KD, Metkari SS. A Conservative Esthetic Rehabilitation of Complicated Tooth Fracture: Two Case Reports. Int J Prosthodont Restor Dent 2013;3(3):96-100.

\section{Source of support: Nil}

\section{Conflict of interest: None}

\section{INTRODUCTION}

Anterior teeth are commonly traumatized in orofacial injuries associated with automobile accidents, ${ }^{1}$ sport injuries, violence or fall; leading to crown and/or root fractures. Maxillary incisors are the most commonly encountered teeth in the trauma, whereas the mandibular incisors are less frequently involved due to their natural anatomic position in the dental arch. Among traumatic injuries, uncomplicated crown fracture accounts to more than $50 \%^{2}$ of cases, as where complicated crown fracture accounts to 2 to $13 \%{ }^{3}$ of all dental injuries. The choice of treatment for complicated crown and/or root fractures which involves the pulp depends upon several factors viz the developmental stage of a tooth, time lapsed between the occurrence of an accident and the treatment rendered as well as concomitant periodontal injury. $^{3}$

Crown root fracture is usually characterized by diagonal fracture line that usually starts coronal to marginal gingiva and extends beyond the gingival crevice. Clinically, the displacement of coronal fractured fragment may be either minimal due to holding of fractured segments together by underlying gingival tissue or may be completely detached exposing the underlying pulp.

Treatment modalities considered for such fractured teeth includes composites, fragment reattachment, laminate or esthetic crown. Among which, the tooth fragment reattachment is considered to be the most conservative, biologic and an esthetic approach. Fragment reattachment as a treatment of choice for crown or crown-root fracture depends upon the tooth fragment availability, ${ }^{4,5}$ the extent of the fracture line, an invasion of the biologic width, an endodontic involvement, the occlusion, an esthetics and its prognosis. ${ }^{6}$ Tennery was the first to report the reattachment of a fractured fragment using acid-etch technique. Subsequently, Starkey and Simonsen have also reported fragment reattachment cases. ${ }^{7,8}$ Reattachment of fractured anterior tooth fragment is an easy, less time consuming and comparatively economical method than other expensive prosthetic alternatives. Reattached fragment to a greater extent restores esthetics by maintaining the original tooth's shape, color, translucency, function ${ }^{9}$ and also gives positive psychological feeling to the patient by retaining their natural tooth in the oral cavity. ${ }^{10}$

In cases of uncomplicated crown fracture, only reattachment of fragment using suitable bonding materials suffice the restorative need where as in cases of complicated crown-root fracture, after endodontic treatment of involved tooth; the subgingival fracture line should be principally converted into supragingival fracture line using either gingivectomy, flap surgery or orthodontic extrusion, followed by fragment reattachment. Chosack and Eildeman in 1964 described the reattachment of tooth fragment in a 12 years old child by reattachment of coronal fragment after endodontic treatment of involved tooth with post placement. ${ }^{11}$ Studies evident that fragment reattachment treatment approach is usually durable and the primary cause of loss of attached tooth fragment is introduction of new dental trauma or nonphysiological use of the restored tooth. ${ }^{12}$

\section{CASE REPORT}

\section{Case 1}

An apparently healthy 25-year-old female reported to the department of conservative dentistry and endodontics, with a complaint of moderate pain on mastication in tooth 42 , since a week after a fall on the ground. Clinically, the tooth 42 was tender to percussion. The crown fragment of 
tooth 42 showed complicated crown-root fracture extended subgingivally on the distolabial area and attached with fibrous gingival attachment with labial gingiva (Fig. 1A). Radiographic examination revealed fracture line involving pulp and widening of periodontal space in tooth 42 (Fig. 1B). After taking informed consent of patient, local anesthesia was administered and the mobile crown fragment of tooth 42 was carefully detached from the tooth and stored in the physiologic saline and exposed crown-root interface was examined (Figs $1 \mathrm{C}$ and D).

On thorough clinical examination, endodontic treatment is advised in tooth 42 and the functional-esthetic treatment options ${ }^{13,14}$ were presented to the patient, which include:

1. Reattachment of the fractured fragment or

2. Esthetic veneer or

3. Post-core and crown.

Reattachment option was presented only after confirming that the available tooth fragment was in good condition and that was fitted reasonably well on the tooth. After discussing

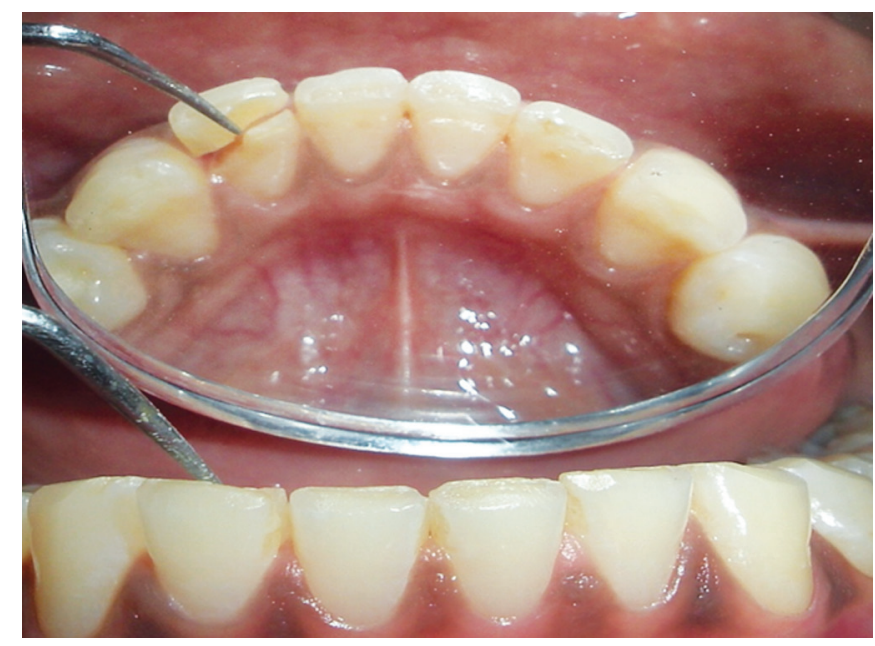

Fig. 1A: Preoperative lingual view (mirror view) showing fracture line in tooth 42 (Case 1)

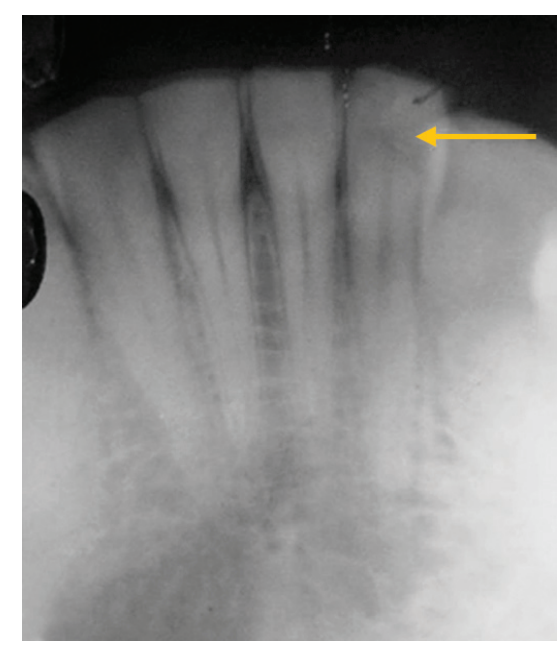

Fig. 1B: Preoperative radiograph showing complicated fracture in tooth 42 (Case 1) the advantages, disadvantages, prognosis and overall cost of each treatment option, the patient agreed for the tooth fragment reattachment procedure with intraradicular fiber post anchorage. A single visit endodontic treatment of tooth 42 was accomplished using crown down preparation technique and root canal was obturated using resin sealer with gutta percha by lateral condensation technique. To visualize the approximation of the fragment, the subgingival fractured margin was converted into supragingival margin by gingivectomy procedure using yttrium scandium gallium garnet (YSGG) soft tissue laser having a wavelength of $2790 \mathrm{~nm}$. Subsequently smoothening of the rough cemental surface was carried out using composite finishing bur to facilitate early soft tissue attachment and healing. Light transmitting glass fiber post was selected on the radiograph and its length was adjusted. Intraradicular post space was prepared and dentinal grooving (Figs 1E and F) was done in the fractured fragment so that the coronal portion

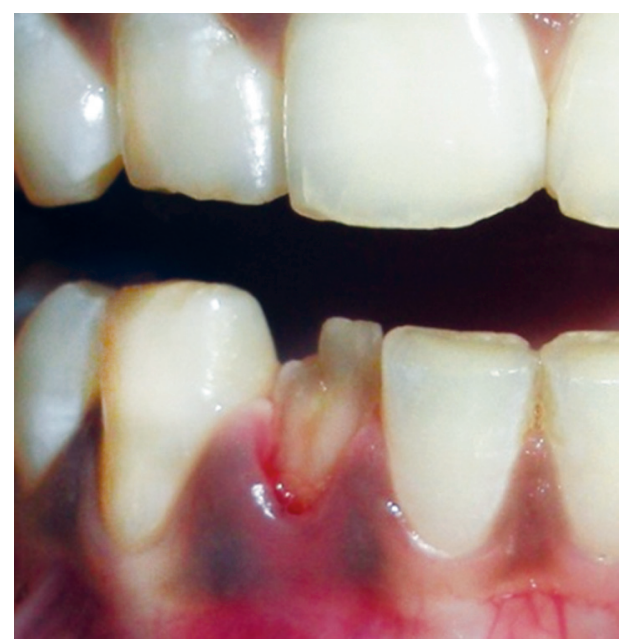

Fig. 1C: Photograph after fragment removal (Case 1)

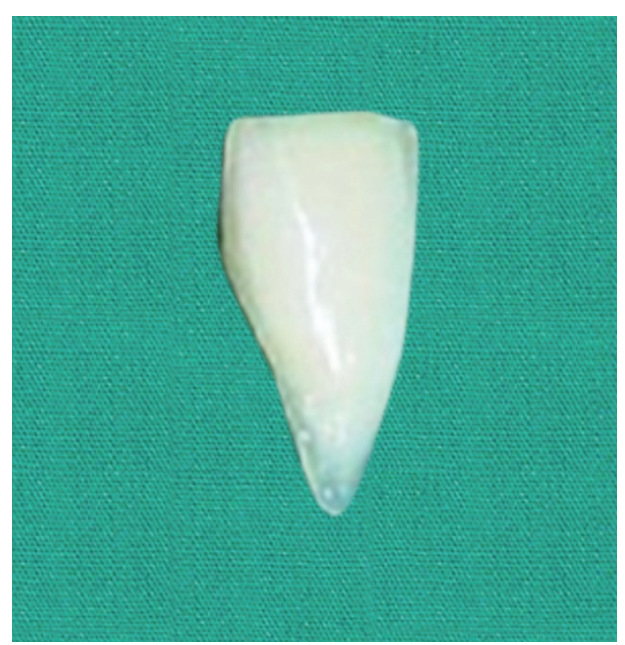

Fig. 1D: Retrieved tooth fragment (Case 1) 


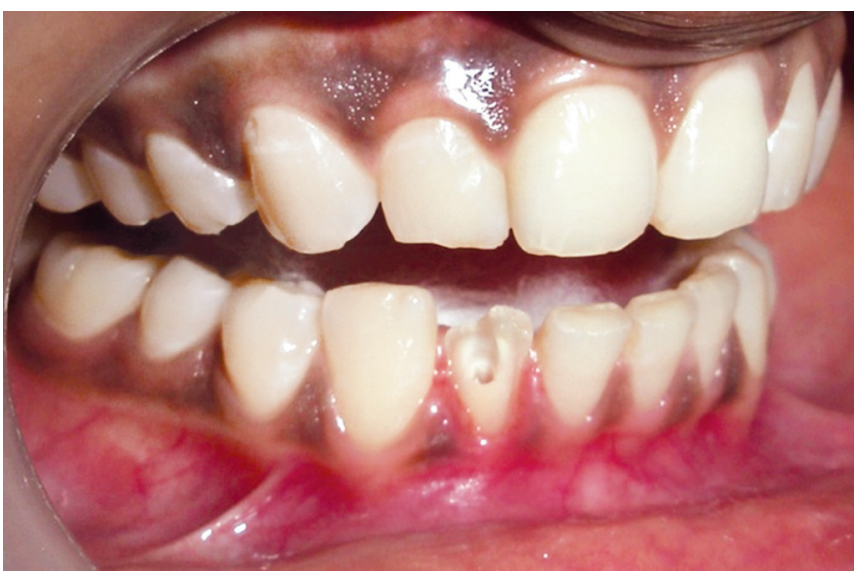

Fig. 1E: Photograph after gingivectomy followed by post space preparation in tooth 42 (Case 1)

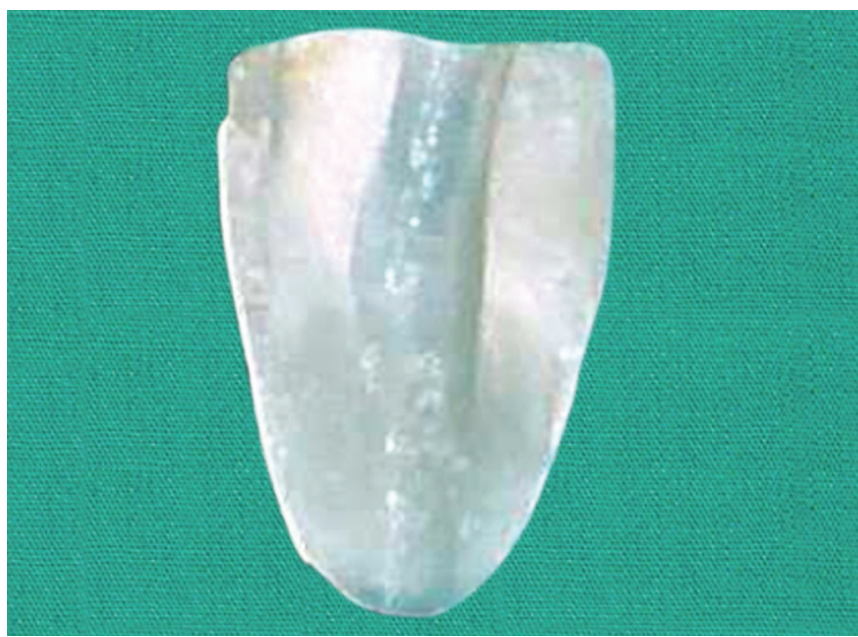

Fig. 1F: Tooth fragment with dentinal groove preparation (Case 1)

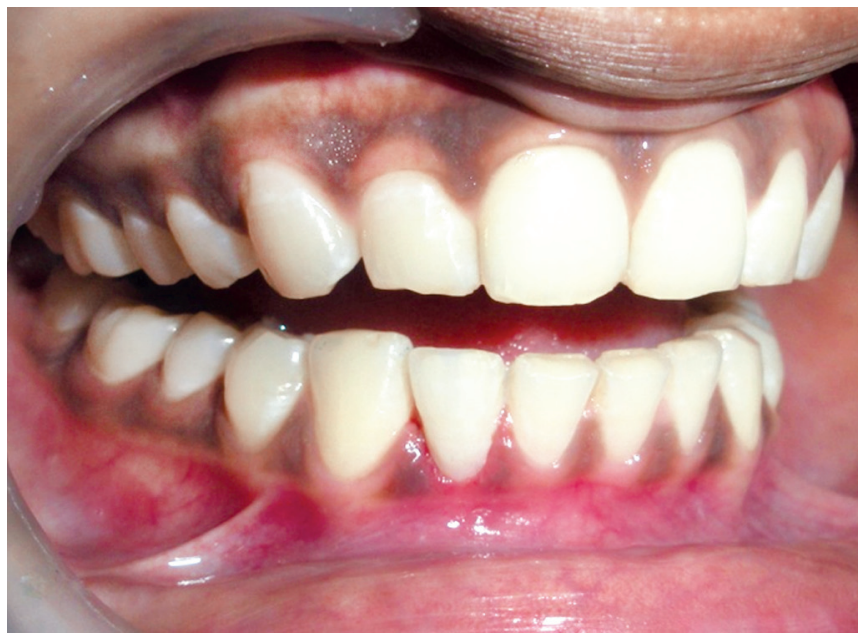

Fig. 1G: Postoperative photograph of restored tooth 42 (Case 1)

of post should pass through the crown fragment until total approximation of the tooth fragment with tooth was achieved.

Acid etching for both crown fragment and intraradicular space of the tooth 42 using $37 \%$ phosphoric acid gel was carried out, followed by rinsing, bonding agent application and light curing. After confirmation of the proper approximation of the tooth fragment, the prepared post space was filled with dual cure resin luting cement. The light transmitting fiber post and the fragment were positioned as determined before with firm digital pressure and remaining excess cement was removed immediately. The area was light cured for 20 seconds on each surface, confirming no displacement had occurred before complete polymerization. Final finishing of the margin was carried out with Sof-Lex disks.

The occlusion was re-evaluated and adjusted accordingly. Patient was instructed regarding avoidance of heavy functional load on this tooth and to follow proper oral hygiene methods. Patient was recalled after a week for revaluation. The immediate postoperative view (Fig. 1G) showed optimum esthetic results with restored functionality by a very conservative and cost-effective approach.

\section{Case 2}

An apparently healthy 37 -year-old male reported to the department of conservative dentistry and endodontics, with a complaint of fractured tooth and severe pain associated tooth 11 after an accidental blow of hammer on the face occurred during automobile work 2 hours back. Clinical examination showed laceration on upper lip with evidence of bleeding and tooth 11 was fractured (Ellis class III fracture) exposing pulp at cervical third level (Fig. 2). Patient reported with the fractured tooth fragment stored in water container carried along with him (Figs $3 \mathrm{~A}$ and B). Radiographic examination revealed the fracture crown involving pulp in tooth 11. After thorough discussion and taking informed consent of patient, it was decided to reattach the fractured tooth fragment with the fiber post anchorage. The tooth fragment was stored then in the physiologic saline and after securing local anesthesia single visit endodontic treatment was accomplished in tooth 11. Post space was prepared and post length was adjusted (Fig. 3C). Tooth fragment was prepared to accommodate coronal part of the post and complete approximation of the fragment with the tooth was assured. Fiber post was bonded using dual cure resin luting cement and the tooth fragment was restored to its natural position with firm digital pressure (Fig. 3D). The occlusion was evaluated and adjusted. The patient was recalled after a week and instructed regarding the care and maintenance for proper oral hygiene methods.

\section{DISCUSSION}

Reattachment of the fractured fragment is considered to be one of the most conservative treatment modalities for 


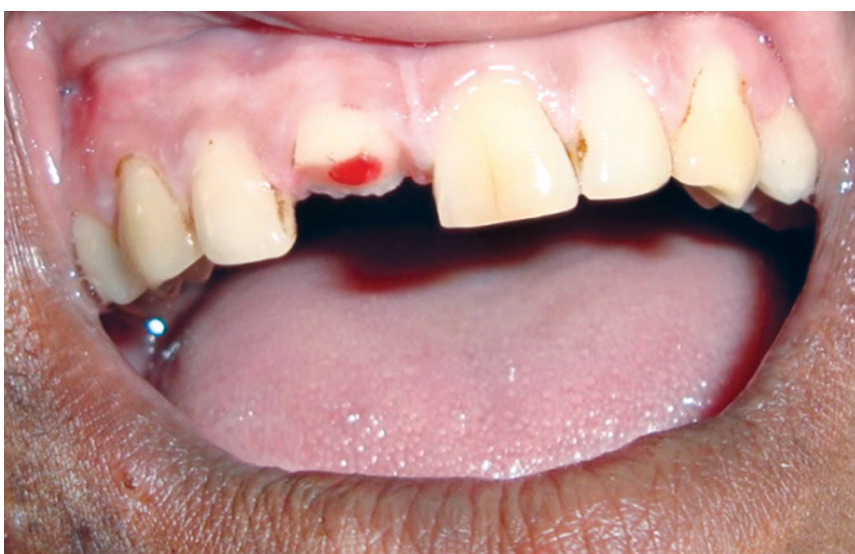

Fig. 2: Preoperative photograph (labial view) showing complicated crown fracture in tooth 11 (Case 1)

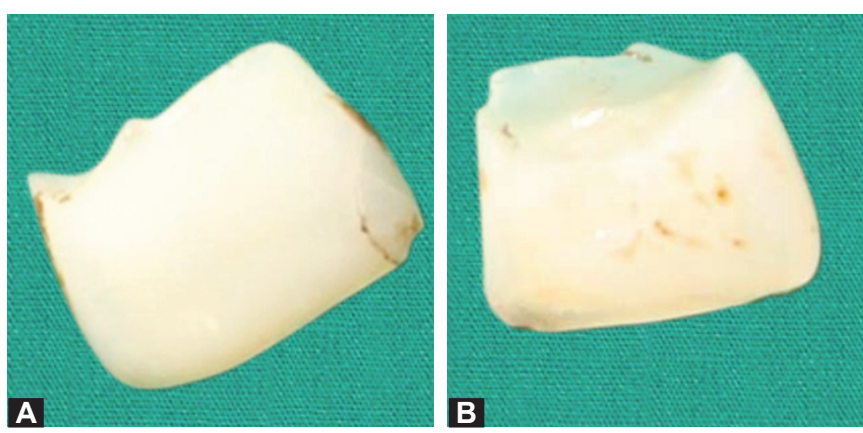

Figs $3 A$ and $B$ : Tooth fragment of tooth 11 :

(A) labial view, (B) palatal view (Case 2)

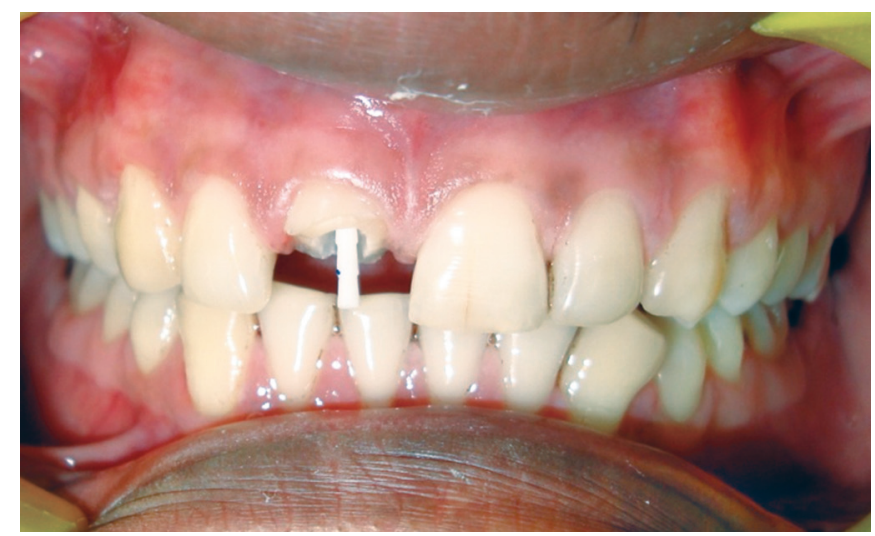

Fig. 3C: After fiber postcementation in tooth 11 (Case 2)

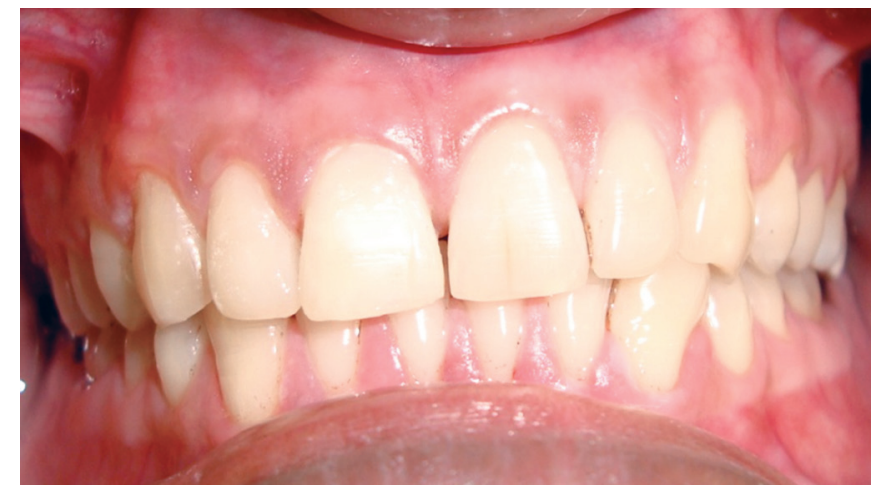

Fig. 3D: Postoperative photograph of restored tooth 11 (Case 2) restoration of fractured anterior teeth; provided intact tooth fragment is available. Numerous advantages of fragment reattachment makes it favorable treatment of choice with incorporation of suitable design features like bevel designs, chamfers, dentinal and enamel grooves which have increased the retention and the fracture strength of the reattached fragment.

\section{CONCLUSION}

Traumatic dental injuries are more common in children and adolescents and in such a traumatic event fragment reattachment can be considered to a faster, conservative, esthetic and psychologically acceptable remedy.

\section{REFERENCES}

1. Andreasen JO, Andreasen FM. Textbook and Color Atlas of Traumatic Injuries to the Teeth. 3rd ed. St Louis, MO: Mosby. 1994.p.151-155.

2. Andreason JO. Tooth and bone loss related to dental trauma. In: Koch G, Bergendal T, Kvint S, editors. Consensus conference on oral implants in young patients. Stockholm: Forlagshuset Gothia AB. 1996. p. 40-45.

3. Andreason JO, Andreason FM. Crown fractures. Textbook and Color Atlas of Traumatic Injuries to the teeth, 3rd ed. Copenhagen; Munksgaard. 1993;p.219-256.

4. Simonsen RJ. Traumatic fracture restorations: An alternative use of the acid etch technique. Quint Int 1979;10(2):15-22.

5. Baratieri LN, Ritter AV, Junior SM, Filho JCM. Tooth fragment reattachment: an alternative for restoration of fractured anterior teeth. Pract Periodont Aesthet Dent 1998;10:115-127.

6. Olsburgh S, Jacoby T, Krejci I. Crown fractures in the permanent dentition: pulpal and restorative considerations. Dent Traumatol 2002;18(3):103-115.

7. Starkey PE. Reattachment of a fractured fragment to a tooth. J Ind Dent Assoc 1979;58:37-38.

8. Simonsen RJ. Restoration of a fractured central incisor using original teeth. J Am Dent Assoc 1982;105:646-648.

9. Chu FCS, Yim TM, Wei SHY. Clinical considerations for reattachment of tooth fragments. Quint Int 2000;31:385-391.

10. Baratieri LN, Monteiro S. Tooth fracture reattachment: Case reports. Quint Int 1990;21:261-270.

11. Chosack A, Eildeman E. Rehabilitation of fractured incisor using the patient's natural crown. Case report. J Dent Child 1964;31: 19-21.

12. Andreasen FM, Noren JG, Andreasen JO, et al. Long-term survival of fragment bonding in the treatment of fractured crowns. Quintessence Int 1995;26:669-681.

13. Reis A, Loguercio AD, Kraul A, Matson E. Reattachment of fractured teeth: a review of literature regarding technique and materials. Oper Dent 2004;29(2):226-233.

14. Rappelli G, Massaccesi C, Putignano A. Clinical procedures for the immediate reattachment of a tooth fragment. Dent Traumatol 2002;18(5):281-284. 


\section{ABOUT THE AUTHORS}

\section{Manoj Mahadeo Ramugade (Corresponding Author)}

Assistant Professor, Department of Conservative Dentistry and Endodontics, Nair Hospital Dental College, Mumbai, Maharashtra India, Phone: 9664541227, e-mail: manojramu05@yahoo.co.in

\section{Neelam Dilip Chandwani}

Reader, Department of Conservative Dentistry and Endodontics Sharad Pawar Dental College, Wardha, Maharashtra, India

\section{Kishor Dattatray Sapkale}

Assistant Professor, Department of Conservative Dentistry and Endodontics, Nair Hospital Dental College, Mumbai, Maharashtra India

\section{Sachin Shashikant Metkari}

Assistant Professor, Department of Conservative Dentistry and Endodontics, Nair Hospital Dental College, Mumbai, Maharashtra India 